\title{
ANNOUNCEMENT OF MEETING
}

\section{An international symposium on tropical studies resource availability and the structure and functioning of tropical ecosystems}

\author{
Celebrating the Silver Anniversary of the founding of the \\ Organization for Tropical Studies (OTS) \\ Honorary President: Professor Francois Boulière, Université de Paris \\ Co-sponsored by the Association for Tropical Biology
}

University of Miami, Coral Gables, Florida and San Jose, Costa Rica

\section{5-12 June 1988}

The Organization for Tropical Studies (OTS) is convening a major international symposium on tropical studies in June 1988 to celebrate the Silver Anniversary of its founding. The symposium will last one week and will consist of North American sessions and a second component in Costa Rica, where most OTS field activities have been located. The North American portion of the symposium will be hosted by the University of Miami, where OTS was founded in 1963.

The theme of the symposium is Resource availability and the structure and functioning of tropical ecosystems. Soils of the humid tropics face climates with the greatest weathering and nutrient-leaching potentials of any in the world. Nutrient availability to plants is a key variable whose effects extend throughout the ecosystem and influences the rate of efficiency of nutrient cycling. Nutrient availability may also determine the proportion of primary production that is harvestable by herbivores, with ramifications throughout the food web. Availability of nutrients and other resources also affects plant competitive interactions and thereby plant community structure. The symposium will aim for a new synthesis of data and ideas on the significance of resource availability in ecology and evolutionary biology. The symposium will focus on intertropical comparisons involving the major tropical land masses of the world.

An understanding of the effects of nutrient availability on ecosystems will aid in devising strategies for rehabilitating soils impoverished by deforestation and mismanagement and developing sustainable agriculture and forestry. The symposium will provide a forum that will lead to important advances in management of tropical ecosystems by focusing on a key unifying variable.

The Costa Rican sessions will highlight conservation of natural resources in the country that has been the host for many of OTS's activities in its first 25 years. The Costa Rican portion of the symposium will be the culmination of a week long national focus on the environment, La Semana del Medio Ambiente. In 1988, the OTS Silver Anniversary Symposium will be the central event of that week.

\section{Programme and organization}

Plenary sessions, Miami:

Soil fertility, nutrient cycling, and the decomposer food web.

Resource availability and plant community structure.

Resource availability and plant-herbivore interactions.

Resource availability and food-web structure.

Resource availability and sustainable development: management of productivity and diversity for human needs in the 21 st century.

San Jose:

Conservation biology in Latin America in light of the Costa Rican experience.

The proceedings of the symposium, to appear as a special supplement to Biotropica, will provide an authoritative synthesis of the cutting edge of research on key issues facing the tropics.

For further information, contact: Dr Jay M. Savage, Silver Anniversary Symposium, Department of Biology, University of Miami, PO Box 249118, Coral Gables, FL 33124, USA. 